\title{
Análise das bulas de medicamentos fitoterápicos comercializados em Porto Alegre, RS, Brasil
}

\author{
Bello, C. M. ${ }^{1}$ Montanha, J. A.*1; Schenkel, E. P. ${ }^{2}$ \\ ${ }^{1}$ Faculdade de Farmácia, Universidade Federal do Rio Grande do Sul, Porto Alegre, RS; \\ ${ }^{2}$ Departamento de Ciências Farmacêuticas, Centro de Ciências da Saúde, \\ Universidade Federal de Santa Catarina, Florianópolis, SC.
}

Recebido para publicação em: 31/07/2002 Aceito para publicação em: 18/11/2002

\begin{abstract}
RESUMO: Com o objetivo de avaliar a qualidade das bulas de medicamentos fitoterápicos em relação à presença das frases obrigatórias por lei, bem como de informações específicas exigidas pela legislação de medicamentos fitoterápicos, foram selecionados 65 produtos em farmácias de Porto Alegre contendo pelo menos uma das seguintes plantas medicinais: maracujá, boldo, alcachofra, guaraná e sene. Através de um formulário, analisou-se a presença das frases exigidas pela Portaria 110/97 da ANVS, que regulamenta as bulas de medicamentos, e das informações exigidas pela Resolução RDC 17/00 da ANVS, sobre registro de medicamentos fitoterápicos. A maioria dos produtos analisados não possui bula, e em nenhum deles verificouse a presença de todas a frases e demais informações exigidas pela legislação vigente. Especialmente significante foi a inexistência de dados sobre reações adversas, contra-indicações e advertências. Foi possível concluir que as bulas de medicamentos fitoterápicos analisados não seguem as normas legais, são incompletas e deficientes de informações, podendo induzir a sérios problemas de saúde.
\end{abstract}

Unitermos: Medicamentos fitoterápicos; bulas; farmacovigilância.

ABSTRACT: Analysis of phytomedicines package inserts commercialized in Porto Alegre, RS, Brazil. Sixty-five products with one of the following medicinal plants: passion flower, boldus, artichoke, guarana and senne were acquired in drugstores of Porto Alegre, RS, Brazil. These products were analyzed in order to evaluate the quality of phytomedicines package inserts in relation to the obligatory informations required by the Brazilian drug legislation. Most of the products did not have package inserts, and none of them presented all informations required by the legislation. Furthermore, most of them omitted the potential occurrence of adverse effects, contra-indications and precautions. In conclusion, the analyzed package inserts did not followed the Brazilian drug regulation, were incomplete and showed deficiencies which can induce health consumer problems.

Key words: herbal medicines; package inserts; pharmacovigilance. 


\section{INTRODUÇÃO}

Até o início do século XIX, os recursos terapêuticos eram constituídos predominantemente por plantas e/ou extratos vegetais e esses recursos não diferiam muito dos remédios utilizados hoje em dia na medicina popular (SCHENKEL et al., 2002). Com o desenvolvimento da química, em meados do século $X X$, os medicamentos de origem sintética tomaram aos poucos o lugar das plantas medicinais. Apesar disso, nos últimos anos, vem ocorrendo um retorno ao uso de plantas medicinais e medicamentos elaborados a partir destas, não apenas em países considerados pobres, como também nos desenvolvidos.

Prova disso, é que as vendas de fitoterápicos resultam em aproximadamente quatro bilhões de dólares por ano nos Estados Unidos, e foi estimado que pelo menos um em três americanos utilizou plantas medicinais em 1998 (MAR e BENT, 1999). Outro indicador da importância atribuída é a extensa produção de literatura especializada, contemplando aspectos sobre o uso terapêutico destes recursos medicinais, como por exemplo, MARK (2000) e DERMARDEROSIAN (2001).

Na Europa, uma investigação, conduzida em 1991, mostrou que 1.400 medicamentos fitoterápicos eram usados na União Européia, e as vendas desses, em 1994, chegaram a seis bilhões de dólares. A Alemanha lidera as vendas com 2,5 bilhões de dólares, seguida pela França com 1,6 bilhões e a Itália, com 600 milhões de dólares (KELLER, 1996).

Apesar da importante retomada da utilização dos medicamentos fitoterápicos, ainda existe poucas informações sobre esse tipo de medicamento, mesmo para farmacêuticos e médicos, que estão buscando mais detalhes acessíveis e confiáveis sobre o assunto (GRAUDS, 1996).

No Brasil, a bula representa o principal material informativo fornecido aos pacientes na aquisição de medicamentos (SILVA et al., 2000). A obrigatoriedade de inclusão da bula na embalagem de medicamentos é regulamentada pela Portaria 110/97 da ANVISA (BRASIL, 1997).

Apesar da crescente importância dos medicamentos fitoterápicos no Brasil, somente em 1995 foi elaborada uma legislação específica, através da Portaria 6/MS/SNVS (BRASIL, 1995), a qual foi discutida amplamente, através de sucessivas consultas públicas, resultando na RDC 17/ 2000 da ANVISA (BRASIL, 2000a).

O que motivou a realização deste trabalho foi a preocupação com a adequação das informações fornecidas no Brasil aos usuários de medicamentos fitoterápicos e, baseando-se nas exigências da legislação vigente no Brasil, realizou-se a análise das informações presentes nos textos de bulas de alguns dos fitotérápicos mais vendidos em farmácias de Porto Alegre.

\section{MÉTODO}

\section{Amostragem}

Realizou-se um levantamento em 13 farmácias escolhidas de forma aleatória em três bairros diferentes da cidade de Porto Alegre, Estado do Rio Grande do Sul, no mês de janeiro de 2001, através de entrevistas com balconistas ou farmacêuticos, utilizando-se a seguinte questão: "Medicamentos fitoterápicos a base de quais plantas são mais vendidos na sua farmácia?". A partir das respostas, tomou-se conhecimento dos produtos contendo as plantas mais citadas.

\section{Organização e análise dos dados}

Foi desenvolvido um formulário, considerando a RDC 17/2000 da ANVISA (BRASIL, 2000a), baseado em outro anteriormente elaborado por Silva et al. (2000), que contemplava especificamente a Portaria 110/97 da ANVISA (BRASIL, 1997). 
Por intermédio desse formulário procurou-se analisar a presença das frases obrigatórias, de formato padronizado pela Portaria 110/97 da ANVISA, e dos dizeres legais (registro do produto no MS ou indicação de registro, farmacêutico responsável e número do registro profissional, nome da empresa, endereço e CGC). Considerando-se a RDC 17/2000 da ANVISA (BRASIL, 2000a), foi verificada a existência do nome botânico oficial da planta, parte da planta utilizada e da composição do medicamento (relação real, em peso ou volume, da matéria-prima vegetal usada e a correspondência em marcadores e/ou substâncias ativas). Foi observado, ainda, se existiam dizeres legalmente proibidos, indutores da automedicação, e a designação "medicamento fitoterápico" ou "medicamento tradicional" (BRASIL, 2000a). Os dados foram inseridos em planilhas criadas no programa Microsoft Excel ${ }^{\circledR}$, versão 1997.

\section{RESULTADOS}

Constatou-se que, dentre os fitoterápicos mencionados, os que tiveram o maior número de citações pelas farmácias continham: guaraná, maracujá, sene, alcachofra e boldo. O maracujá (Passiflora spp.) fazia parte da composição de 15 produtos, o boldo (Peumus boldus Molina) de 17, a alcachofra (Cynara scolymus L.) de 18 produtos, o guaraná (Paullinia cupana Kunth) de 13 e o sene (Senna alexandrina Mill.) de 13 produtos.

Dos 65 produtos analisados, 33 (51\%) não possuíam bula, de forma que os percentuais das Tabelas 1 a 4 foram calculados com base no total de produtos com bula. Com relação às plantas, foram analisadas as bulas de 11 produtos contendo maracujá, de sete contendo boldo, de 13 contendo alcachofra, de oito contendo guaraná e de três contendo sene. Boldo e sene foram as plantas que mais apresentaram produtos sem bula dentro da embalagem (59\% e $77 \%$, respectivamente).

\section{Presença de frases obrigatórias}

Os percentuais relacionados à presença das frases obrigatórias estão listados na Tabela 1 , sendo apresentada, mais freqüentemente, a frase obrigatória que alertava para manter o medicamento longe do alcance das crianças.

Tabela 1. Percentuais da presença de frases obrigatórias, exigidas pela Portaria 110/97 (ANVISA), nas bulas analisadas.

\section{Frases obrig atórias}

Percentual

"Todo medicamento deve ser mantido fora do alcance das crianças" 64

"Informe seu médico a ocorrência de gravidez na vigência do tratamento ou após o seu término"

"Informar ao médico se está amamentando"

"Não deve ser ingerido durante gravidez e lactação."

0

"Siga a orientação do seu médico, respeitando sempre os horários, as doses e a duração do tratamento"

"Não interromper o tratamento sem o conhecimento do seu médico"

"Informe seu médico o aparecimento de reações desagradáveis"

"Informe seu médico sobre qualquer medicamento que esteja usando, antes do início, ou durante o tratamento"

"Não tome remédio sem o conhecimento do seu médico pode ser perigoso para a saúde" 


\section{Presença de informações específicas}

A freqüência de informações específicas foi mais elevada que a de frases obrigatórias, e está apresentada na Tabela 2.

Tabela 2. Percentuais de informações específicas, presentes nas bulas analisadas.

\begin{tabular}{l|c}
\multicolumn{1}{c|}{$\quad$ Informações específicas } & Percentual \\
\hline Ação esperada do medicamento & 100 \\
Cuidados de armazenamento & 75,8 \\
Prazo de validade & 51,5 \\
Gravidez e lactação & 57,6 \\
Cuidados de administração & 88 \\
Informações sobre interrupção do tratamento & 12,1 \\
Informações sobre reações adversas & 57,6 \\
Ingestão concomitante com outras substâncias & 30,3 \\
Informações sobre contra-indicações e precauções de uso & 75,8
\end{tabular}

\section{Indicações de uso}

Também foi avaliado se as indicações restringiam-se apenas às oficiais, constantes no anexo 1 da RDC 17/2000 da ANVISA (BRASIL, 2000a), e às indicações constantes na bibliografia de referência (BLUMENTHAL, 1998). Esses dados podem ser melhor visualizados na Tabela 3.

Tabela 3. Percentuais de indicações presentes, nas bulas analisadas, citadas na bibliografia oficial (RDC 17/2000 da ANVISA) e de referência (BLUMENTHAL, 1998).

\begin{tabular}{|c|c|c|c|c|}
\hline Planta & $\%$ & $\begin{array}{c}\text { Indicações da } \\
\text { Resolução RDC } \\
17 / 2000\end{array}$ & $\begin{array}{l}\text { Indicações da } \\
\text { Comissão E }\end{array}$ & Outra indicações citadas nas bulas \\
\hline Alcachofra & 15 & $\begin{array}{l}\text { colerético, } \\
\text { hepatoprotetor e } \\
\text { colagogo }\end{array}$ & $\begin{array}{l}\text { ação: colerética } \\
\text { uso: dispepsia }\end{array}$ & $\begin{array}{l}\text { Reumatismo crônico } \\
\text { Tratamento de diabetes } \\
\text { Tratamento racional da obesidade }\end{array}$ \\
\hline Boldo & 6 & $\begin{array}{l}\text { colagogo e } \\
\text { colerético }\end{array}$ & $\begin{array}{l}\text { ação: antiespasmódico, coleréti- } \\
\text { co e para aumento da secreção } \\
\text { gástrica } \\
\text { uso: dispepsia, dores suaves no } \\
\text { trato gastrintestinal }\end{array}$ & $\begin{array}{l}\text { Laxante } \\
\text { Para diarréia } \\
\text { Auxiliar no emagrecimento } \\
\text { Antisséptico suave das vias urinárias } \\
\text { Diurético } \\
\text { Para doenças hepáticas crônicas }\end{array}$ \\
\hline Maracujá & 100 & sedativo & $\begin{array}{l}\text { ação: inibidor da motilidade } \\
\text { uso: inquietação nervosa }\end{array}$ & $\begin{array}{l}\text { Coadjuvante neuro-vegetativo } \\
\text { Menopausa } \\
\text { Excitante do SNC }\end{array}$ \\
\hline Sene & 100 & laxante suave & uso: constipação & $\begin{array}{l}\text { Excesso de gordura } \\
\text { Ação não agressiva para a mucosa } \\
\text { intestinal }\end{array}$ \\
\hline Guaraná & 100 & não é citado & não é citado & $\begin{array}{l}\text { Afrodisíaco na impotência sexual } \\
\text { Paralisia cerebral }\end{array}$ \\
\hline
\end{tabular}


Das indicações, que não seguiram o especificado na RDC 17/2000 da ANVISA e nas referências utilizadas, foram muito citadas pelas bulas: as ações diurética e hipocolesterolemiante para a alcachofra, as propriedades estimulantes sexuais para o guaraná e as indicações de ação diurética e laxante para o boldo, como mostra a Tabela 3. Na amostra analisada, $43 \%$ das bulas substituiu a frase obrigatória, que atentava sobre o "modo de administração", pela seguinte frase: "Siga corretamente o modo de usar, não desaparecendo os sintomas, procure orientação médica". Para as drogas vegetais com preparo através de infusão ou decocção, a maioria das informações sobre administração se resumia ao modo de preparo.

Um problema marcante foi a apresentação, em muitas bulas, de indicações atribuídas ao produto e indicações específicas para cada planta, indicando erroneamente que as propriedades e ações pudessem ser separadas para cada componente da formulação. Esse fenômeno foi observado em cerca de $30 \%$ dos produtos contendo sene, $40 \%$ dos produtos contendo guaraná e $50 \%$ dos produtos contendo alcachofra.

Foi informado por $12 \%$ das bulas que os respectivos produtos não causavam reações adversas nem apresentavam contra-indicações, sem justificativa para tal ausência.

\section{Presença de dizeres legais}

Quanto aos dizeres legais, conforme a Tabela 4, a maioria das bulas apresentou algum tipo de indicação de registro, seja pelo número de protocolo, código de isenção, ou pelo próprio número de registro. Muitos produtos se auto-isentavam de registro justificando tal isenção através da Portaria 741/98 da ANVISA (BRASIL, 1998a), que permitia a comercialização em todo território nacional dos alimentos constante em tal lista, mediante prévia protocolização nas Vigilâncias Sanitárias, e da Resolução 23/2000 da ANVISA (BRASIL, 2000b), que dispensa alimentos, vendidos como chás e vegetais dessecados ou liofilizados, da obrigatoriedade de registro.

Tabela 4. Percentuais da presença dos dizeres legais, nas bulas analisadas.

\section{Dizeres Legais}

Número de Registro no MS

Número de Protocolo no MS

Auto-isenção

Número de registro inexistente

Número de Registro no MS incompleto e/ou incorreto

Farmacêutico responsável e inscrição profissional

Nome da empresa

Endereço

Cadastro geral do contribuinte

\section{Percentual}

15

15

6

15

45

49

49

49 


\section{Presença de informações, segundo a RDC 17/2000 da ANVISA}

Quanto a esta Resolução, 93\% das bulas apresentaram nomenclatura botânica oficial, $57 \%$ citaram o autor do binômio, $45 \%$ a família botânica, $60 \%$ a parte utilizada da planta e nenhuma bula descreveu a composição do medicamento (relação real, em peso ou volume, da matériaprima vegetal usada e a correspondência em marcadores e/ou substâncias ativas).

Quanto à presença dos nomes científicos, foram observados os seguintes percentuais, para cada espécie vegetal estudada: alcachofra -100\%; guaraná $-87 \%$; maracujá $-91 \%$; boldo $-86 \%$ e sene $-100 \%$. Também constatou-se que alguns nomes científicos e a designação do(s) autor(es) do binômio estavam redigidos de forma incorreta ou incompleta.

\section{DISCUSSÃO}

De um modo geral, os resultados obtidos nesse estudo indicam que as bulas dos medicamentos fitoterápicos, encontrados no mercado farmacêutico em Porto Alegre, necessitam de uma padronização das informações. O fenômeno observado já vem sendo apontado reiteradamente, por exemplo, por Mentz e Schenkel, (1989) e por ZAUPA et al. (2000).

Um fato importante a destacar é que $51 \%$ dos produtos da amostra analisada não possuíam bula, o que ilustra o descaso pelas informações nos medicamentos fitoterápicos. Isto indica a comercialização de um elevado número de produtos ilegais, uma vez que não atendem a preceitos vigentes sobre a estrutura da bula, interpretação essa confirmada quando se observa o elevado percentual de produtos que não apresentam os números de registro, de acordo com a legislação vigente.

Muitos produtos justificam a ausência de registro pela Portaria 741/98 da ANVISA (BRASIL, 1998a), porém essa legislação não isenta de registro, mas apenas dos testes de identidade e qualidade. Além disso, a alcachofra e os extratos vegetais com ela preparados foram retirados da Portaria 741/98 da ANVISA pela Resolução 15/2000 da ANVISA (BRASIL, 2000c).

Uma confusão observada diz respeito à comercialização de plantas como chás, para uso como alimento e/ou medicamento. Embora a Portaria 519/1998 da ANVISA (BRASIL, 1998b) classifique o boldo entre chás (produtos constituídos de partes vegetais inteiras, fragmentadas ou moídas, onde não devem constar do rótulo dizeres induzindo a utilização terapêutica), alguns produtos contendo esta espécie vegetal e comercializados como chás, possuem dizeres de finalidade terapêutica em suas embalagens, caracterizando-os como medicamentos. Por outro lado, o sene, o guaraná, a alcachofra e o maracujá não estão listados na Portaria mencionada, mas vem sendo comercializados como chás.

Apesar da maioria das embalagens não apresentar dizeres induzindo à auto-medicação, poucas continham a designação "medicamento fitoterápico", o que indica, novamente, que a grande parte dos produtos são considerados "alimentos" pelos seus fabricantes. A ausência da declaração de farmacêutico responsável e a falta de um padrão nos números de registro comprovam que as autoridades sanitárias não estavam controlando suficientemente a comercialização de produtos derivados de plantas medicinais, em meados de 2001, nem a adequação dos mesmos para sua utilização como alimento ou como medicamento. Por outro lado, como pode se constatar através das Resoluções da ANVISA, em 2001 e início de 2002 (ver http/www.anvisa.gov.br), vários laboratórios vem sendo autuados e fechados pela Vigilância 
Sanitária, por produzirem medicamentos fitoterápicos sem registro no Ministério da Saúde, alguns deles com bulas inclusas nesse estudo.

Os dados obtidos pela verificação da presença das frases obrigatórias são preocupantes, pois a maioria dos fitoterápicos não está de acordo com a Portaria 110/97 da ANVISA (BRASIL, 1997).

O fato de parte da amostra não apresentar informações sobre reações adversas $(42,4 \%)$, contra-indicações $(24,2 \%)$, uso na gravidez e lactação $(42,4 \%)$, interrupção do tratamento (78\%) e ingestão concomitante com outras substâncias (70\%) pode induzir o pensamento de que os medicamentos fitoterápicos são produtos sem toxicidade e contra-indicações e que qualquer pessoa pode consumi-los, independente da idade ou estado de saúde.

A ausência destas informações é comprometedora, por exemplo, quando se trata de medicamentos fitoterápicos à base de sene, pois é conhecido que o uso prolongado de sene pode levar à dependência (ciclo vicioso) e que além dos efeitos adversos gastrintestinais, pode ocorrer interação com vários medicamentos, e seu uso é contra-indicado durante o período de amamentação (BLUMENTHAL, 1998).

A maioria dos medicamentos fitoterápicos analisados, à base de sene e boldo, não possui bula. O maracujá e, principalmente, o boldo, que pode ser comercializado como chá, têm toxicidade documentada (ALMEIDA et al., 2000; FISHER et al., 2000), e o boldo mostrou ser teratogênico e abortivo em ratos (ALMEIDA et al., 2000). Já para o guaraná, uma planta com alta concentração de cafeína e, também, com importantes efeitos adversos e contraindicações, principalmente na gestação e lactação (DERMADEROSIAN, 2001), a ausência de informações pode colocar em risco a saúde do paciente, pelo fato de ser normalmente dispensado sem prescrição médica.

A presença das informações sobre indicações de uso ou ação esperada do medicamento em $100 \%$ das bulas poderia ser considerado um bom indicativo, porém muitas bulas tinham estas como, praticamente, as únicas informações. Este fato leva a concluir que as bulas parecem expressar a preocupação da indústria em exaltar, principalmente, as propriedades benéficas do produto, de forma semelhante a uma propaganda, não salientando outras informações que deveriam compor a bula, segundo a Portaria 110/97 da ANVISA (BRASIL, 1997).

Um dos problemas detectados foi a grande quantidade de bulas com indicações para regimes de emagrecimento e para redução de celulite, principalmente, nos produtos contendo sene e alcachofra. Como foi também verificado, a alcachofra e o boldo foram as plantas que continham o maior número de indicações, além das citadas na RDC 17/2000 da ANVISA (BRASIL, 2000a) e na bibliografia de referência (BLUMENTHAL, 1998). Esse uso indiscriminado, sem orientação médica, e com indicações duvidosas, pode ser perigoso para o paciente, sendo muitas vezes, agravado pela falta de informações fidedignas.

No momento atual, em que a produção de medicamentos fitoterápicos, vem sendo considerada como uma importante alternativa para o desenvolvimento da indústria farmacêutica nacional, esperar-se-ia qualidade nas informações apresentadas aos usuários. No entanto, os resultados obtidos neste trabalho indicam que as informações apresentadas nas bulas dos medicamentos fitoterápicos são incompletas e, em muitos casos, desrespeitam a legislação vigente.

Segundo o Código de Proteção do Consumidor (BRASIL, 1990), todo cidadão tem como direito básico o acesso à informação adequada e clara sobre diferentes produtos e serviços, mas esse direito não tem sido respeitado pelas indústrias de medicamentos fitoterápicos. 


\section{REFERÊNCIAS BIBLIOGRÁFICAS}

ALMEIDA, E.R.; MELO, A.M.; XAVIER, H. Toxicological evaluation of the hydroalcoholic extract of the dry leaves of Peumus boldus and boldine in rats. Phytotherapy Research, v.14, p.99-102, 2000.

BLUMENTHAL, M. The Complete German Comission E Monographs : Therapeutic Guide to Herbal Medicines. Austin: American Botanical Council, 1998.

BRASIL, 1990. Lei 8.078 de 11 de setembro de 1990, Diário Oficial da União, Brasília, DF: Poder Legislativo, 12.09.1990.

BRASIL, 1995. Ministério da Saúde. Secretaria de Vigilância Sanitária. Portaria 6, de 31.01.1995. Institui e normatiza o registro de produtos fitoterápicos junto ao Sistema de Vigilância Sanitária. [Disponível em: http://www.anvisa.gov.br]. Acesso em 09 Junho 2001.

BRASIL, 1997. Ministério da Saúde. Agência Nacional de Vigilância Sanitária. Portaria 110, de 10.03.1997. Institui roteiro para texto de bula de medicamentos, cujos itens devem ser rigorosamente obedecidos, quanto à ordem e conteúdo. [Disponível em: http://www.anvisa.gov.br]. Acesso em 09 Junho 2001.

BRASIL, 1998a. Ministério da Saúde. Secretaria de Vigilância Sanitária. Portaria 741, de 16.09.1998. Portaria alterada pelas Resoluções n.323, de 21 de julho de 1999, RE n.9, de 4 de novembro de 1999 e RE n.30, de 8 de dezembro de 1999. [Disponível em: http://www.anvisa.gov.br]. Acesso em 09 Junho 2001.

BRASIL, 1998b. Ministério da Saúde. Secretaria de Vigilância Sanitária. Portaria 519, de 26.06.1998. Aprova o Regulamento Técnico para Fixação de Identidade e Qualidade de "Chás - Plantas Destinadas à Preparação de Infusões ou Decocções", constante do Anexo desta Portaria. [Disponível em: http://www.anvisa.gov.br]. Acesso em 09 Junho 2001.

BRASIL, 2000a. Ministério da Saúde. Agência Nacional de Vigilância Sanitária. Resolução RDC 17, de 24.02.2000. Dispõe sobre o registro de medicamentos fitoterápicos. [Disponível em: http://www.anvisa.gov.br]. Acesso em 09 Junho 2001.

BRASIL, 2000b. Ministério da Saúde. Agência Nacional de Vigilância Sanitária. Resolução 23, de 15. 03.2000. Dispõe sobre O Manual de Procedimentos Básicos para Registro e Dispensa da Obrigatoriedade de Registro de Produtos Pertinentes à Área de Alimentos. [Disponível em: http://www.anvisa.gov.br]. Acesso em 09 Junho 2001.

BRASIL, 2000c. Ministério da Saúde. Agência Nacional de Vigilância Sanitária. Resolução RE 15, de 08. 02.2000. [Disponível em: http://www.anvisa.gov.br]. Acesso em 09 Junho 2001.

DERMARDEROSIAN, A. (Ed.). The review of natural products - the most complete source of natural products information. In: Facts and Comparisons. Missouri: Wolters Kluwer, 2001.

FISHER, A.A.; PURCELL, P.; LE COUTEUR, D.G. Toxicity of Passiflora incarnata L. Journal of Toxicology and Clinical Toxicology, v.38, p.63-66, 2000.

GRAUDS, C. Natural medicines in pharmacy texts, medical schools and government research. Pharmacy Times, v.62, p.92, 1996.

KELLER, K. Herbal medicinal products in Germany and Europe: experiences with national and European assessment. Drug Information Journal, v.30, p.933-948, 1996.

MAR, C.; BENT S. An evidence-based review of the 10 most commonly used herbs. Western Journal of Medicine, v.171, p.168-171, 1999.

MARK B. (Ed.). Herbal Medicine. CD-ROM para Windows 95/98. Austin: American Botanical Council, 2000. MENTZ, L. A.; SCHENKEL, E. P. Plantas medicinais: a coerência e a confiabilidade das indicações terapêuticas. Caderno de Farmácia, v. 5, n.1/2, p.93-119, 1989.

SCHENKEL, E. P.; GOSMANN, G.; PETROVICK, P.R. Produtos de origem vegetal e o desenvolvimento de medicamentos. In: SIMÕES, C.M.O; SCHENKEL, E.P.; GOSMANN, G.; DE MELLO, J.C.P.; MENTZ, L.A.;

Rev. Bras. Farmacogn., v. 12, n. 2, jul.-dez. 2002. 
PETROVICK, P.R. (Org.). Farmacognosia. Da planta ao medicamento. 4. ed. Porto Alegre: Editora Universidade; Florianópolis: Ed. da UFSC, p.301-330, 2002.

SILVA, T.; DAL-PIZZOL, F.; BELLO, C. M.; MENGUE, S. S.; SCHENKEL, E. P. Bulas de medicamentos e a informação adequada ao paciente. Revista de Saúde Pública, v.34, p.184-189, 2000.

ZAUPA, C.; CHANQUE, A.L.S.; SILVA, C.C.; CARRASCHI, L. A.; MARQUES, L.C.; Vigilância Sanitária de Fitoterápicos - I: controle de qualidade farmacobotânico e legal dos produtos comercializados nas farmácias e ervanários de Maringá - PR. Caderno de Resumos dos Trabalhos Científicos do IX Encontro Estadual de Farmacêuticos e Bioquímicos; VII Congresso Catarinense de Farmacêuticos e Bioquímicos; I Encontro de Farmacêuticos e Bioquímicos do Mercosul. Florianópolis: Sindicato dos Farmacêuticos do Estado de Santa Catarina, p.33-34, 2000.

*Autor para correspondência:

Prof. Dr. Jarbas Alves Montanha

Faculdade de Farmácia - Universidade Federal do Rio Grande do Sul

Avenida Ipiranga, 2752

90640-000 - Porto Alegre - RS

E-mail: montanha@farmacia.ufrgs.br 